\title{
Scheduling pumped hydro power storage systems under price and flow uncertainty
}

\author{
Ahmet Yucekaya, Seda S. Metin \\ Department of Industrial Engineering, Kadir Has University, Fatih, Istanbul, Turkey
}

Email address:

ahmety@khas.edu.tr(A. Yucekaya)

To cite this article:

Ahmet Yucekaya, Seda S. Metin. Scheduling Pumped Hydro Power Storage Systems under Price and Flow Uncertainty. International Journal of Environmental Monitoring and Analysis. Vol. 1, No. 5, 2013, pp. 188-193. doi: 10.11648/j.ijema.20130105.14

\begin{abstract}
Hydroelectric power plants are important energy resources as they are environmentally friendly, have low level of potential risks and they are relatively cheap. If properly utilized, it can replace some thermal power plants and hence decrease the harmful effects to the environment. A Pumped Hydro Storage System which is a special type of hydroelectric power plant can be used to store energy and to use the water more efficiently. When the energy demand and the energy price are high (peak hours), the water at upper reservoir is used to generate electricity and the water is stored in the lower reservoir. Revenue is gained from the power sale to the market. When the demand and the energy price are low (off peak hours), the water at lower reservoir is pumped back to the upper reservoir. Cheap electricity is used to pump the water. The hourly market price and water inflow are uncertain. The main objective of a company is to find an operation schedule that will maximize its revenue. In this paper we develop a model that includes hourly inflow and power price data and delivers an operation schedule. Historical water inflow and power price data are used to generate scenarios. A real case study is developed to validate the model based on the historical river data and electricity prices.
\end{abstract}

Keywords: Pumped Hydro Storage Systems, Electricity Price, Optimization, Scheduling

\section{Introduction}

It is still expensive and not technologically efficient to store electrical energy. As a result the electricity is still stored in other forms such as magnetic, mechanical and chemical energy. If a large amount of energy need to be stored, the most efficient and economic options are Pumped Hydro Storage System (PHSS) and Compressed Air Storage Systems (CAES). PHSS systems are more efficient compared to CAES and they have lower cost and longer economic life.

The working principle of the system simple but yet sophisticated. There are at least two water reservoirs in this system, the large reservoir is at the upper level and the smaller one is in the lower level. There are electricity generation units and pumping units between two reservoirs. The water is used to generate electricity and it is released from the upper reservoir to the lower level reservoir. This electricity is generated and sold when the electricity is most needed and the electricity price is high. These periods are called on-peak times and are usually day time until the midnight. The electricity price is low on off-peak time. The water in the lower reservoir is stored or used to generate electricity in generation units on the small reservoir. Or it can be pumped again to the upper reservoir to be used to generate electricity later on-peak times. Hence, the water can be recycled whenever it is needed. In other words, the potential energy is stored in one reservoir to be converted to electrical energy later (Kapsalli, 2012). Figure 1 presents a typical PHSS system.

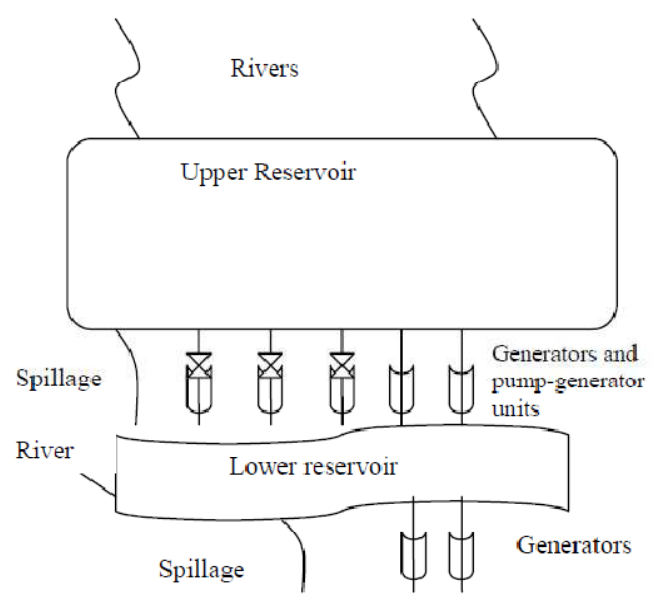

Figure 1: A systemic view of PHSS 
A PHSS can also be used to balance the load changes as it has a fast ramp-up rate and quick response. First PHSS power plants were built in 1890 in Italy and Sweden. But their commercial usage was started in early 1930's and major developments took place after the II. World War. Their importance has increased after the liberalization and deregulation of power markets as they became economic (Yang, 2012).

In Yang and Jackson, 2011, it is mentioned that pumped hydro storages are the best low-carbon electricity resource because that the other options cannot flexibly adjust their output to match instable electricity demand. Pumped hydro storage systems are more efficient than other low-carbon electricity resources which are nuclear, wind and solar system. It is indicated that pumped hydro storage systems provide many commercial advantages for the producers. Pumped hydro storage systems serves to stabilize the electricity grid through peak shaving, reserve generation, load balancing and frequency control. It is also noted that while global warming increasing rapidly, developers is working new pumped hydro storage system projects and in 2014 its expected capacity worldwide is $76 \mathrm{GW}$.

Zhu et al.,2006, mentioned that hydropower plants are prepared with an optimum plan for the least operation cost, maximum reservoir management and maximum proportion of electricity generation. In Zhao and Davison, 2009a, a simple model for the operation of pumped hydro storage facility is developed. It is assumed that there are timevarying but deterministics electricity prices and constant water inflows. The objective is to optimize the energy and profit produced by the plants (Zhao and Davison, 2009b).

(Ikodu, 2009) develops an optimization model for the scheduling of a pumped hydro power plant. The model consider uncertainty of market prices and inflow rates. The dynamic programming model maximizes the expected profit from the operation of the plant given that there is markov based inflow rates and many price scenarios.

Through the literature, it is shown that the pumped hydro storage systems are more efficient and essential low-carbon level resources. However, it is also obvious that an efficient and effective operation of the system is needed given that there are deregulated power prices and variable water inflow. The remainder of the paper is as follows. Section 3 provides the model formulation and the solution methodology. Section 4 includes a case study developed for a PHSS system. The conclusions are given in Section 5.

\section{Model Development and Solution Methodology}

The objective of a PHSS operator is to schedule the system to maximize its profit given power sale price and purchase price. There are also operational constrains that need to be considered. As a result, a model that include all constraints and prove a generation and pumping schedule that will maximize the profit. The notation of the model is provided in appendix. The operational purpose is to maximize the profit of operation of PHSS which is revenue of power sale minus cost of power purchase as :

$$
\operatorname{Max} \sum_{t=1}^{T}\left(\sum_{i=1}^{I} M_{t}^{1} Q_{i, t}^{1}+\sum_{j=1}^{J} M_{t}^{2} Q_{j, t}^{2}-\sum_{k=1}^{K} M_{t}^{1} P_{k, t}\right)
$$

Assume a PHSS system given in Figure 1. The first part in the objective function is the sales revenue gained from the upper reservoir which is generated power by each unit multiplied with the power price. The second part is the revenue gained from the generator units at the lower reservoir. The last part is the cost of purchased power for pumping units which is calculated by multiplying the power amount and purchase price.

There are also operational constraints that need to be included as follows:

$$
\begin{aligned}
& 0 \leq Q_{i, t}^{1} \leq Q_{i, c a p}^{1} \quad \forall i, t \\
& 0 \leq Q_{i, t}^{2} \leq Q_{i, c a p}^{2} \quad \forall i, t \\
& 0 \leq P_{k, t} \leq P_{k, \text { cap }} \quad \forall k, t \\
& \sum_{i=1}^{I} Q_{i, t}^{1} \sum_{k=1}^{K} P_{k, t}=0 \quad \forall k, t \\
& V_{t}^{1}=V_{t-1}^{1}+\sum_{k=1}^{K} E_{k}^{0} P_{k, t}-\sum_{i=1}^{I} E_{i}^{1} Q_{i, t}^{1}+I_{t}^{1}-S_{t}^{1} \quad \forall t \\
& V_{t}^{2}=V_{t-1}^{2}-\sum_{k=1}^{K} E_{k}^{0} P_{k, t}+\sum_{i=1}^{I} E_{i}^{1} Q_{i, t}^{1}+\sum_{j=1}^{J} E_{j}^{1} Q_{j, t}^{1}+I_{t}^{2}+S_{t}^{1}-S_{t}^{2} \quad \forall t \\
& V_{\text {min,t }}^{1} \leq V_{t}^{1} \leq V_{\text {max }, t}^{1} \quad \forall t \\
& V_{\min , t}^{2} \leq V_{t}^{2} \leq V_{\max , t}^{2} \quad \forall t \\
& I_{t}^{1}=I_{t}^{a}+I_{t}^{b} \quad \forall t
\end{aligned}
$$

Eq (2) and (3) limit the amount of power generation for units in upper reservoir and lower reservoir with their capacities respectively. Eq (4) shows the limit for pumping units. These constraints basically ensure that capacity limits are not violated.

Some water tunnels are used both for generation and pumping water. It is not possible to generate electricity and pump water at the same time. Hence, eq(5) ensures that only one of these activities take place at any given time. $\mathrm{Eq}(6)$ represents the amount of water in upper reservoir at time $t$. The amount of water in upper reservoir at time $t$ is equal to accumulation of amount of water at time $t-1$, amount of water that is pumped to from the lower reservoir, and amount of water that added with rivers. Some of the water is used to generate electricity and some water can be 
spilled when too much water exists in the reservoir. $\operatorname{Eq}(7)$ represents the amount of water in lower reservoir at time $t$. This amount is equal to the accumulation of amount of water at time $t-1$, amount of water that is added from the upper reservoir (with generation units and spillage), and amount of water that is added with the river. The amount of water that is pumped up back, used to generate electricity and spilled is deducted from this amount. $\operatorname{Eq}(8)$ and (9) represent the volume limits for both reservoirs. Eq (10) shows that inflow to first reservoir consists of inflow of two rivers.

The amount of water that in each river is uncertain through a year. The seasonal effects play an important role to determine the water level. On the other hand, the electricity price at time is also uncertain. The market mechanisms which include supply and demand determine the market price. A solution methodology that will help a PHSS operator to schedule the system is needed.

Main inputs of the model are the inflow rates of rivers for both reservoirs, the market prices for electricity and characteristics of generating units. Figure 2 provides the model inputs and outputs. The model should include the inputs and turn out an optimum generation and pumping schedule that will maximize the profit given that there is sale revenue and electricity cost. It is expected that generation should occur at the times when the electricity price is high to maximize the sales revenue. It is also expected that the pumping should occur when the price is low to minimize the cost.

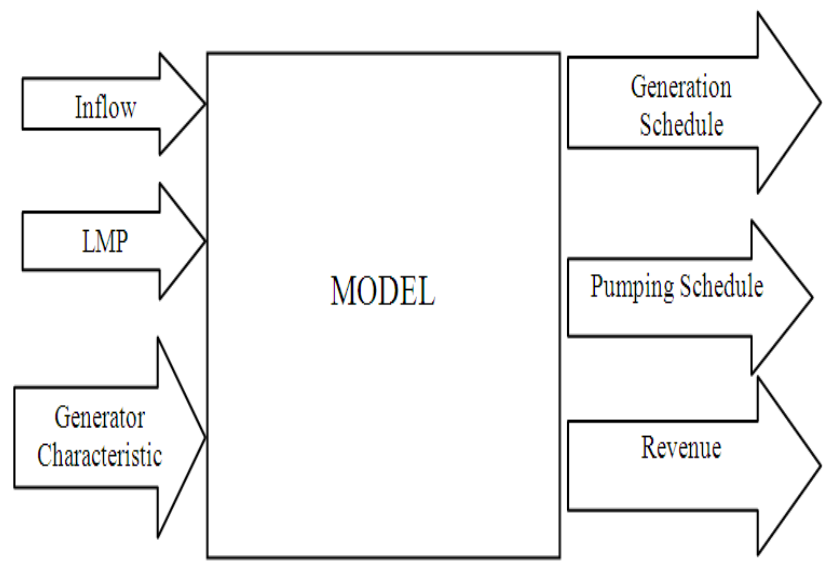

Figure 2: Model Inputs and Outputs

The market prices are determined hourly in deregulated power markets. Hence, the hourly generation and pumping decisions are made. The flow of the solution methodology is determined as given in Figure 3. The algorithm first estimates hourly electricity prices based on the historical prices. Then hourly inflow rates are determined based on the historical estimations.

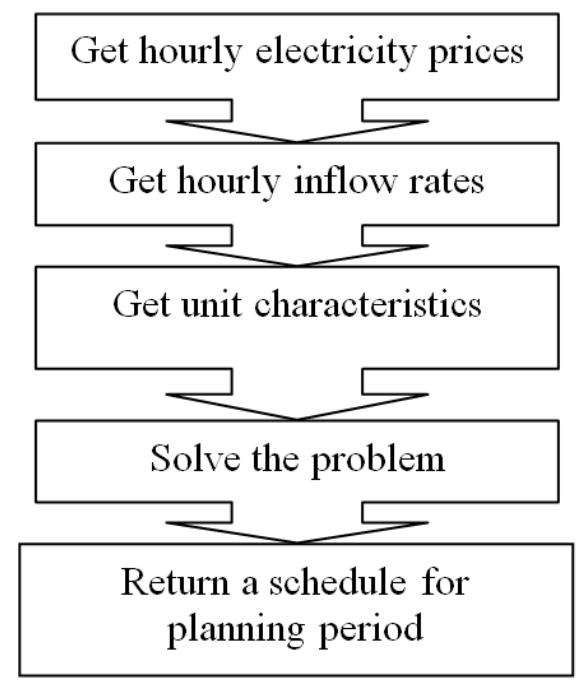

Fig. 3: General Flow Diagram

Finally, the model is solved using a General Algebraic Modeling System (GAMS) which is a high-level modeling system for mathematical programming problems. The software is suitable to build large scale and complex modeling applications. CPLEX 12.5 solver is used which is included in GAMS. A generation and pumping schedule is proposed as an output of the solution algorithm.

\section{Numerical Analysis}

The model is applied for the SmithMountainreservoir which is a PHSS in Virginia, USA. The project was build to generate hydro-electric power with two reservoirs in the near by the Roanoke River, Virginia. Thereservoir, which has two reservoirs namely SmithMountain and Leesville lake, was built on the Roanoke River in the 1960's. Table 1 provides data for both reservoirs. They occupy about 600 miles of shoreline and get round about 25,000 surface acres of water for different uses.

Table 1. Data for the reservoirs

\begin{tabular}{lll}
\hline Reservoir & SmithMountain & Leesville \\
\hline Surface area $\left(\mathrm{km}^{2}\right)$ & 83 & 13.2 \\
Max Depth $(\mathrm{mt})$ & 76 & 9.4 \\
Shore Length $(\mathrm{km})$ & 800 & 32 \\
Length $(\mathrm{km})$ & 96 & 160 \\
Surface elevation $(\mathrm{mt})$ & 242 & 187 \\
\hline
\end{tabular}

The Smith Mountain is the larger and upper reservoir. The reservoir is fed by Roanoke, Back, and Blackwater rivers. The capacity of 5 generation units is $636 \mathrm{MW}$. The water in the SmithMountain is utilized to drive the turbines and generate electricity. This water is stored in Leesville for generating electricity or to pump back to the SmithMountain. SmithMountain has 5 generation units and 
3 pumping units. Table 2 shows the unit characteristics. The pumping units use the same tunnel with the generation units.

Table 2: Unit and Pump characteristics for Smith Mountain

\begin{tabular}{|c|c|c|c|}
\hline \multicolumn{2}{|c|}{ Unit } & Capacity(MW) & Yield(M'/MWh) \\
\hline \multirow{6}{*}{ 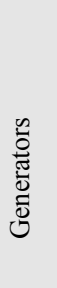 } & 1 & 64.5 & 0.269 \\
\hline & 2 & 177 & 0.273 \\
\hline & 3 & 109 & 0.279 \\
\hline & 4 & 178 & 0.271 \\
\hline & 5 & 68 & 0.280 \\
\hline & 1 & 77 & 0.189 \\
\hline \multirow{2}{*}{ 吊 } & 3 & 127 & 0.213 \\
\hline & 5 & 77 & 0.190 \\
\hline
\end{tabular}

The Leesville lake is the smaller and lower reservoir. The lake is fed by Pigg river and the water flowed from the SmithMountain reservoir. It has two generation units as given in Table 3. The water is either used for electricity generation in these units or to pump back to SmithMountain to use it later.

Table 3: Unit characteristics for Leesville lake

\begin{tabular}{lll}
\hline Unit & Capacity(MW) & Yield(M $\left.\mathbf{M}^{\mathbf{3}} \mathbf{M W h}\right)$ \\
\hline 1 & 22 & 0.736 \\
2 & 22 & 0.736 \\
\hline
\end{tabular}

An important input to the solution algorithm is the hourly market prices for the electricity. The electricity prices are called locational marginal prices (LMP) in USA. The historical prices for the year 2009 are given in Figure 4. Historical prices are stochastic decision variables and they show seasonal variations, depend on load, temperature and work hours (Levine, 2007).

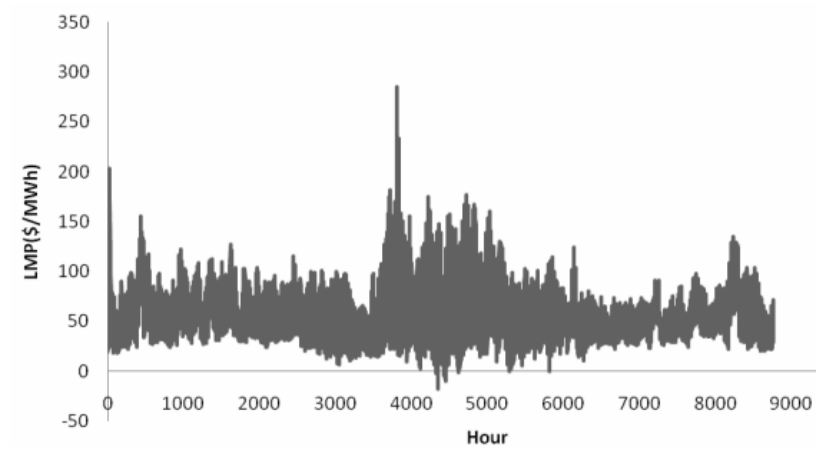

Fig.4. LMP at Smith Mountain and Leesville lake

The market prices effect the results of the optimization model as the objective is to maximize the profit which is revenue minus cost. However, high market prices can be exercised if the water is available in the reservoirs. The amount of water added to the two reservoirs with the inflows of four rivers need to be considered in the model. Figure 5 through 8 provide hourly inflows in 2009 (8760 hours) starting beginning of the year. The water inflows also show variations through the year.Winter and Fall are the periods when much rainfall and runoff are occurred. Summer is the period with lowest inflow.

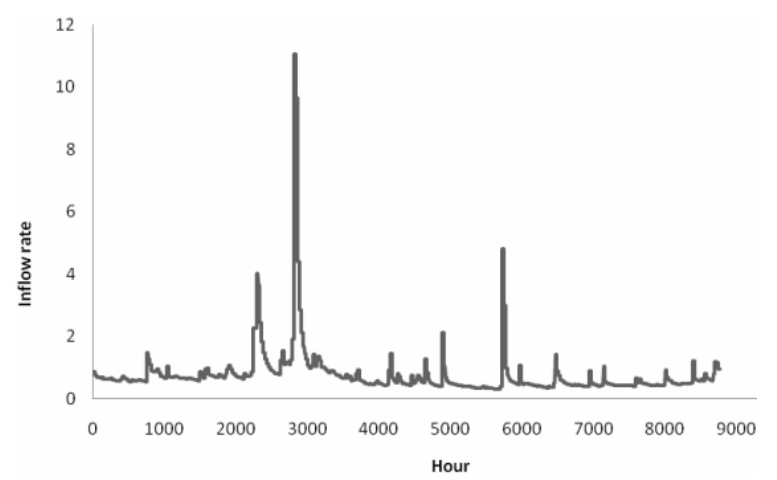

Fig.5. Hourly inflows for Raonake $\left(\mathrm{m}^{3} / \mathrm{hr}\right)$

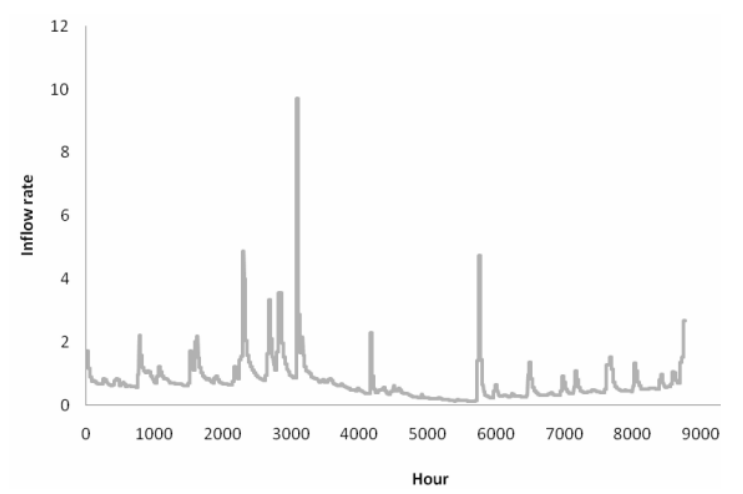

Fig.6. Hourly inflows for Pigg $\left(\mathrm{m}^{3} / \mathrm{hr}\right)$

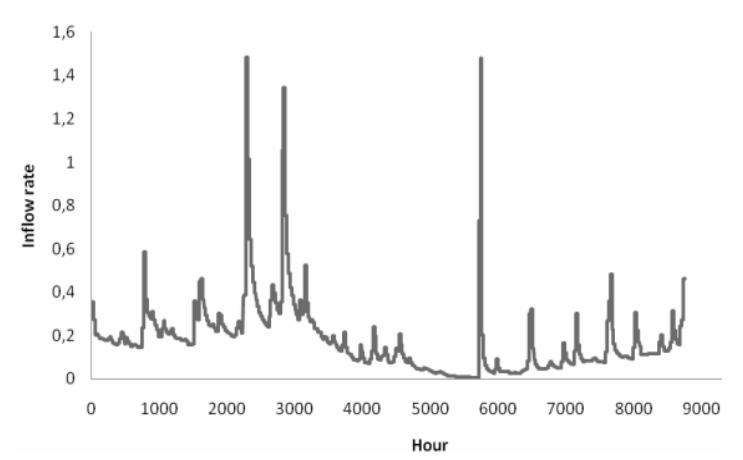

Fig.7. Hourly inflows for Blackwater $\left(\mathrm{m}^{3} / \mathrm{hr}\right)$

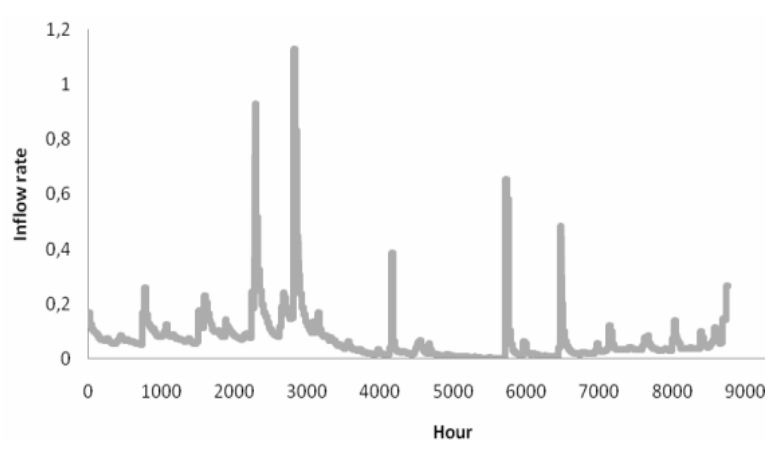

Fig.8. Hourly inflows for Back $\left(\mathrm{m}^{3} / \mathrm{hr}\right)$ 
An optimum generation and pumping schedule can be found with the information of the market price and water level in the reservoirs. For the analysis, we assume that the system operator would like to determine a schedule for the January given that they have historical power prices and water inflows. The system operator forecasts hourly power prices and water inflows and need to determine the optimum generation and pumping schedule. At the beginning of the month, the system operator run the algorithm using the price and flow estimates and determine an operation schedule for one month. Figure 9 show the generation schedule for the first unit at the SmithMountain. When it is economic, the electricity is generated and the water in Smith Mountain reservoir is discharged to the Leesville lake.

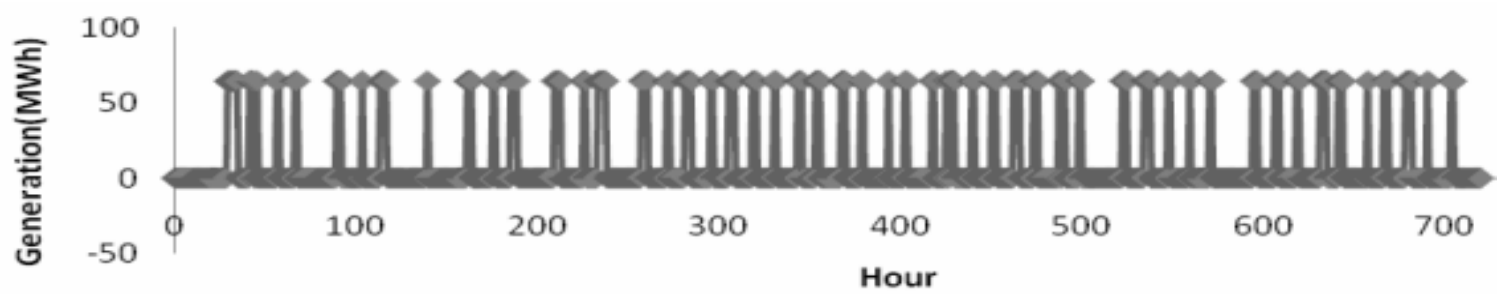

Figure 9. Generation for SmithMountain unit

The discharged water to the Leesville lake is used for electricity generation or it can be pumped back to the SmithMountain reservoir. Figure 10 show the generation schedule in first unit of the Leesville lake. When the electricity price is high enough to generate profit, the generation unit is run and electricity is sold to the market. The water is then discharged and it can no longer be used for power generation.

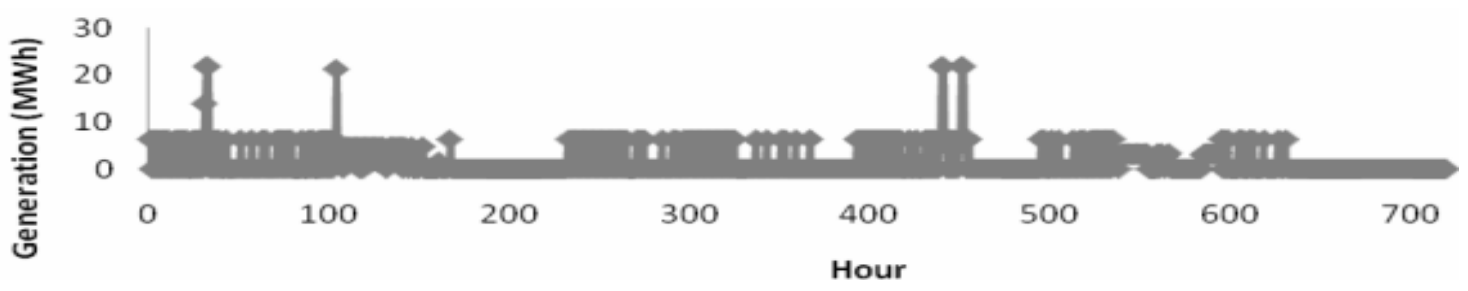

Figure 10. Generation for Leesville unit

If the power price is low, it is not wise to generate electricity as the electricity can be sold with higher prices in other times. If it is economic the water in the Leesville lake can be pumped back to the SmithMountain reservoir using cheap electricity prices. Figure11 provides the pumping schedule for the planning month. It is also important to note that pumping can only be occurred when there is no electricity generation. The power prices are low in nights and weekends and high in daytimes because of the demand. It is expected to have generation in daytime and pumping in nighttime.

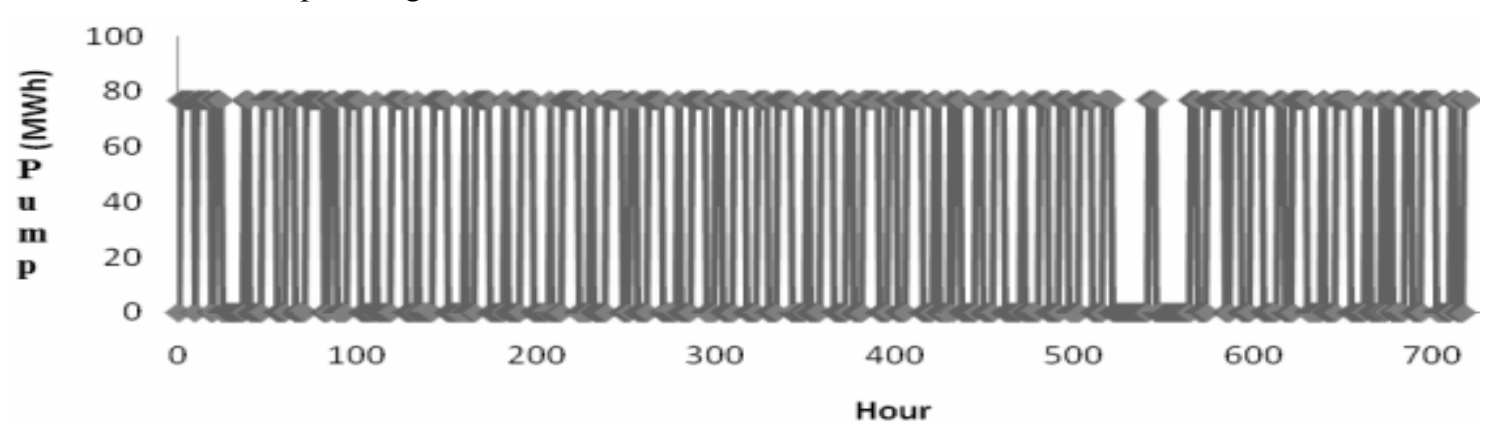

Figure 11. Pumping schedule for the Smith Mountain unit

\section{Conclusion}

In this paper we develop a model for scheduling a PHSS under uncertain electricity price and water inflow rates. The objective is to maximize the profit of the system operator and the model returns an operation schedule that includes generation for the units in upper and lower reservoir and the pumping units. We validate the model for the Smith mountain PHSS. We have shown that if estimated hourly prices and inflow rates which are forecasted based on the historical data are used, an operation schedule can be found for the system operator. In order to extend the research, different scenarios for market prices and inflows can be generated and expected profit can be obtained. The model returned promising results and hence shows that it can be used by power companies for scheduling of PHSS. 


\section{Appendix}

\section{Notation}

$M_{t}^{1}=$ Power market price during hour $\mathrm{t}$ in first reservoir $(\$ / \mathrm{mwh})$

$M_{t}^{2}=$ Power market price during hour $\mathrm{t}$ in second reservoir $(\$ / \mathrm{mwh})$

$Q_{i, t}^{1}=$ Power generated at first reservoir by unit $\mathrm{i}$ in hour $\mathrm{t}(\mathrm{mw})$

$Q_{i, t}^{2}=$ Power generated at second reservoir by unit $\mathrm{j}$ in hour $\mathrm{t}(\mathrm{mw})$

$P_{k, t}=$ Power used for pumping by unit $\mathrm{k}$ during hour $\mathrm{t}$ (mw)

$Q_{i, c a p}^{1}=$ Capacity of first reservoir of unit i (mwh)

$Q_{i, c a p}^{2}=$ Capacity of second reservoir of unit j (mwh)

$P_{k, \text { cap }}=$ Capacity of pumping unit (mwh)

$V_{t}^{1}=$ Volume of first reservoir at the end of hour $\mathrm{t}\left(\mathrm{f} t^{3}\right)$

$V_{t}^{2}=$ Volume of second reservoir at the end of hour $\mathrm{t}$ ( $\mathrm{f}$ $\left.t^{3}\right)$

$I_{t}^{1}=$ Inflow to first reservoir during hour $\mathrm{t}\left(\mathrm{f}^{3}\right)$

$I_{t}^{2}=$ Inflow to second reservoir during hour $\mathrm{t}\left(\mathrm{f}^{t^{3}}\right)$

$I_{t}^{a}, I_{t}^{b}=$ Inflow from rivers a and $\mathrm{b}\left(\mathrm{f} t^{\mathbf{3}}\right)$

$S_{t}^{1}=$ Spillage from first reservoir in hour $\mathrm{t}\left(\mathrm{f}^{\mathbf{3}}\right)$

$S_{t}^{2}=$ Spillage from second reservoir in hour $\mathrm{t}\left(\mathrm{f}^{\iota^{3}}\right)$

$E_{k}^{0}=$ Yield (efficiency) of pump k $\left(\mathrm{ft}^{3} / \mathrm{mw}\right)$

$E_{i}^{1}=$ Yield (efficiency) of generator $\mathrm{i}$ in first reservoir $\left(\mathrm{ft}^{3} / \mathrm{mw}\right)$

$E_{i}^{2}=$ Yield (efficiency) of generator $\mathrm{j}$ in second reservoir $\left(\mathrm{ft}^{3} / \mathrm{mw}\right)$
$V_{\min , t}^{1}, V_{\max , t}^{1}=$ Minimum and maximum limits of first reservoir in hour $\mathrm{t}\left(\mathrm{f}^{\mathbf{3}}\right)$

$V_{\min , t}^{2}, V_{\max , t}^{2}=$ Minimum and maximum limits of second reservoir in hour $\mathrm{t}\left(\mathrm{f} t^{3}\right)$

\section{References}

[1] Ikudo, A, (2009), "Maximizing Gross Margin of a Pumped Storage Hydroelectric Facility under Uncertainty in Price and Water Inflow", M.Sc. Thesis, The Ohio State University avaiable online at: http://etd.ohiolink.edu/sendpdf.cgi/Ikudo\%20Akina.pdf?osu1243970453

[2] Levine, J.G.(2007) "Pumped hydroelectric energy storage and spatial diversity of wind resources as methods of improving utilization of renewable energy sources", Thesis, University of Colorado, available online at: http://www.colorado.edu/engineering/ energystorage/ files/ MSThesis_JGLevine_final.pdf

[3] Kapsalli, M., Kaldellis, J.K., (2010), “Combining hydro and variable wind power generation by means of pumpedstorage under economically viable terms",Applied Energy, Vol. 87(11), pp. 3475-3485

[4] Yang, C, (2012), "Pumped Hydroelectric Storage", Wiley Encyclopedia of Energy, avaible online at:, http://www.duke.edu/ cy42/PHS.pdf

[5] Yang, C.J., Jackson, R.B., (2011), "Opportunities and barriers to pumped-hydro energy storage in the United States", Renewable and Sustainable Energy Reviews, Vol.15, pp. 839-844

[6] Zhao, G, Davison, M., (2009a), "Optimal Control of Hydroelectric Facility Incorporating Pump Storage", Renewable Energy, Vol.34(4), pp.1064-1077.

[7] Zhao, G., Davison, M., (2009b), "Valuing hydrological forecasts for a pumped storage assisted hydro facility", Journal of Hydrology, Vol.373(3-4), pp. 453-462

[8] Zhu, C. J, Zhou, J. Z, Yang, J. J, Wu, W, “Optimal Scheduling of Hydropower Plant with Unceartinity Energy Price Risk", International Conference on Power System Technology, 22-26 October, 2006, Chongqing, China 